\title{
Dermatoscopic aspects of the Microphthalmia with Linear Skin Defects (MLS) Syndrome*
}

\author{
Hiram Larangeira de Almeida Jr. ${ }^{1}$ \\ Luciana Boff de Abreu ${ }^{2}$ \\ Alessandra Banaszeski da Silva ${ }^{3}$
}

\author{
Gabriela Rossi \\ Cristina Bergamaschi \\ Kerstin Kutsche ${ }^{4}$
}

\begin{abstract}
The association of microphthalmia and linear skin defects was named microphthalmia with linear skin defects syndrome (MLS) or MIDAS syndrome (microphthalmia, dermal aplasia, and sclerocornea), an X-chromosomal disorder manifesting mainly in females. We examined a female newborn with facial linear skin defects following the Blaschko lines. Computer tomography and ophthalmological examination confirmed bilateral microphthalmia. An interstitial microdeletion at Xp22.2, encompassing the entire HCCS gene, was identified. Dermatoscopic examination showed erythematous linear areas with telangectasias and absence of sebaceous glands, which appear as brilliant white dots. Vellus hairs were also absent in the red areas. Dermatoscopy could help to establish the diagnosis of MLS/MIDAS syndrome by confirming the aplastic nature of the lesions.
\end{abstract}

Keywords: Congenital abnormalities; Dermoscopy; Genetic diseases, X-linked; Skin diseases, genetic

The association of microphthalmia and linear skin defects was described in the early 1990s. This condition was named microphthalmia with linear skin defects syndrome (MLS) or MIDAS syndrome (microphthalmia, dermal aplasia, and sclerocornea) ${ }^{1-4}$ It can be genetically and clinically distinguished from focal dermal hypoplasia, a condition also associated with linear aplastic defects. ${ }^{1,4}$

We examined a female newborn, who presented congenital facial linear skin defects following the Blaschko lines, some of them covered with hemorrhagic crusts (Figure 1). Computer tomography showed normal central nervous system and small eyes. Ophthalmological examination revealed sclerocornea and confirmed bilateral microphthalmia. A microdeletion of a minimum size of $3 \mathrm{Mb}$ which encompasses one of the two causative genes for MLS syndrome, HCCS at Xp22.25 was detected in the patient but was absent in her mother.

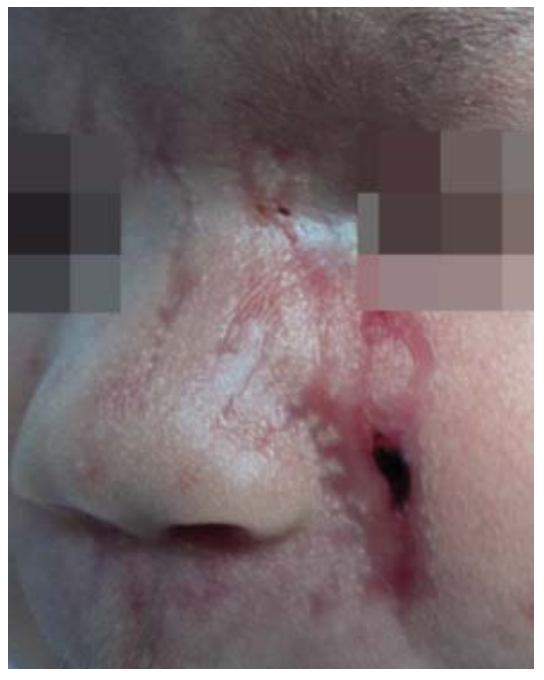

FiguRE 1:

Linear facial defects following the Blaschko lines. 

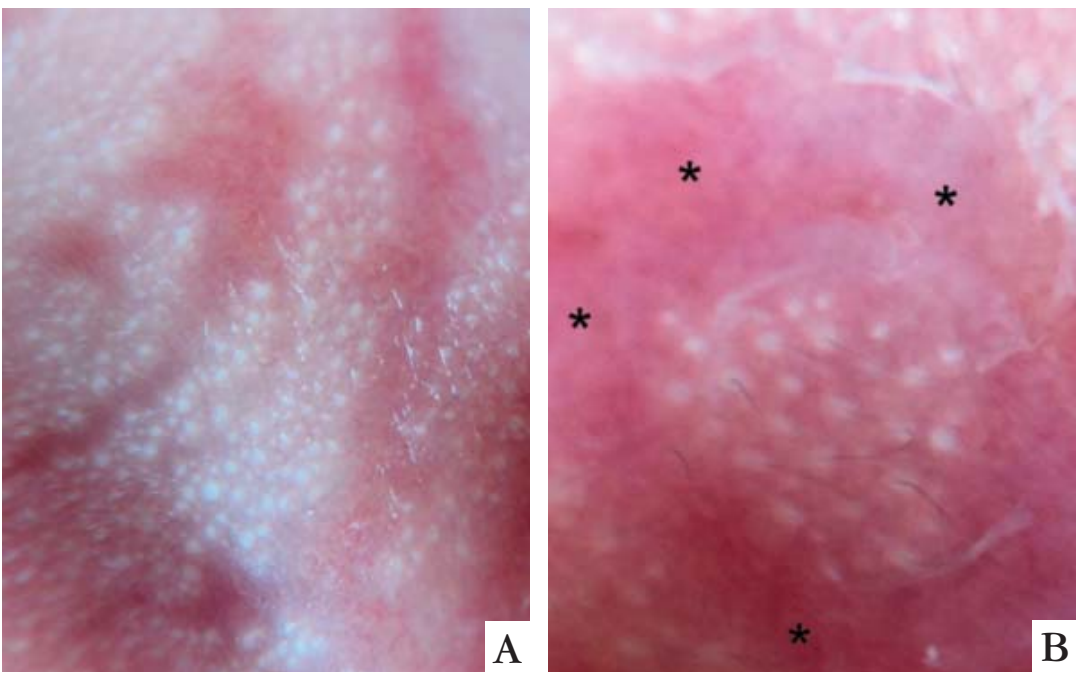

FIGURE 2: Dermatoscopic findings A. linear absence of sebaceous glands (NO brilliant white dots). B. absence of vellus hairs and sebaceous glands in the affected area (asteriscs).

Dermatoscopic examination showed erythematous linear areas with telangectasias and absence of sebaceous glands, which appear as brilliant white dots (Figure 2A). Vellus hairs were also absent in the red areas (Figure 2B).

The skin defects of this peculiar genodermatosis are described as dermal aplasia. It has been linked to segmental aneuploidy of the Xp22.2 region or intragenic mutations in the HCCS gene, which encodes the mitochondrial holocytochrome c-type synthase..$^{5-7}$ To date most cases described have been female and a Xlinked male-lethal trait was suggested., ${ }^{4,6}$ Similar to other $\mathrm{X}$-linked genetic conditions, rare male cases have been described. ${ }^{8}$

Dermatoscopy is widely used in the diagnosis of melanocytic lesions and could also help to establish the diagnosis of MLS syndrome by confirming the aplastic nature of the lesions, with the absence of cutaneous adnexes, such as sebaceous glands and vellus hairs, in a linear distribution. ${ }^{9}$

\section{REFERENCES}

1. al-Gazali LI, Mueller RF, Caine A, Antoniou A, McCartney A, Fitchett M, et al. Two $46, X X, t(X ; Y)$ females with linear skin defects and congenital microphthalmia: a new syndrome at Xp22.3. J Med Genet. 1990;27:59-63.

2. Temple IK, Hurst JA, Hing S, Butler L, Baraitser M. De novo deletion of Xp22.2-pter in a female with linear skin lesions of the face and neck, microphthalmia, and anterior chamber eye anomalies. J M J Med Genet. 1990;27:56-8.

3. Allanson J, Richter S. Linear skin defects and congenital microphthalmia: a new syndrome at Xp22.2 J Med Genet. 1991;28:143-4.

4. Happle R, Daniëls 0, Koopman RJ. MIDAS syndrome (microphthalmia, dermal aplasia, and sclerocornea): an X-linked phenotype distinct from Goltz syndrome. Am J Med Genet. 1993;47:710-3.

5. Wimplinger I, Morleo M, Rosenberger G, laconis D, Orth U, Meinecke P, et al Mutations of the mitochondrial holocytochrome c-type synthase in X-linked dominant microphthalmia with linear skin defects syndrome. Am J Hum Genet. 2006;79:878-89.

6. Wimplinger I, Rauch A, Orth U, Schwarzer U, Trautmann U, Kutsche K. Mother and daughter with a terminal Xp deletion: implication of chromosomal mosaicism and X-inactivation in the high clinical variability of the microphthalmia with linear skin defects (MLS) syndrome. Eur J Med Genet. 2007;50:421-31.
7. Wimplinger I, Shaw GM, Kutsche K. HCCS loss-of-function missense mutation in a female with bilateral microphthalmia and sclerocornea: a novel gene for severe ocular malformations? Mol Vis. 2007;13:1475-82.

8. Anguiano A, Yang X, Felix JK, Hoo JJ. Twin brothers with MIDAS syndrome and XX karyotype. Am J Med Genet A. 2003;119A:47-9.

9. Rezze GG, de Sá BCS, Neves RI. Dermoscopy: the pattern analysis. An Bras Dermatol 2006; 81:261-8
MAILING ADDRESS:
Hiram Larangeira de Almeida Jr
Av. Duque de Caxias 250
96030-001 Pelotas (RS)
Brazil
E-mail: hiramalmeidajr@hotmail.com

How to cite this article: Almeida HL Jr, Rossi G, Abreu LB, Bergamaschi C, Silva AB, Kutsche K. Dermatoscopic aspects of the microphthalmia with linear skin defects (MLS) Syndrome. An Bras Dermatol. 2014;89(1):180-1. 